\title{
PENGARUH TUTOR SEBAYA DALAM PEMBELAJARAN PROBLEM BASED LEARNING TERHADAP KETERAMPILAN BERPIKIR KRITIS FISIKA SISWA SMA
}

\author{
Evi Durotun Nasihah, Supeno, Albertus Djoko Lesmono \\ Program Studi Pendidikan Fisika, FKIP, Universitas Jember \\ Email: eviedurotun@gmail.com
}

Diterima: 28 Januari 2019 Disetujui: 7 Oktober 2019

\begin{abstract}
Abstrak
Penerapan pembelajaran berbasis masalah di kelas sering mengalami hambatan, terutama untuk mengajarkan keterampilan berpikir tingkat tinggi, seperti keterampilan berpikir kritis. Untuk mengatasi kendala ini, dalam penelitian ini kami mencoba menggunakan tutor sebayaa. Penelitian ini bertujuan untuk menggambarkan dampak tutor sebaya dalam pembelajaran berbasis masalah pada keterampilan berpikir kritis siswa fisika SMA. Jenis penelitian ini adalah penelitian eksperimen semu dengan desain kelompok kontrol pretest-posttest. Sampel penelitian ini adalah kelas X MIPA 3 dan X MIPA 4 SMAN 4 Jember. Satu kelas diberi perlakuan menggunakan pembelajaran berbasis masalah disertai dengan bimbingan teman sebaya, sementara satu kelas lainnya hanya menggunakan pembelajaran berbasis masalah. Data tentang keterampilan berpikir kritis diperoleh dari posttest pada akhir pembelajaran yang kemudian dianalisis menggunakan Independent T-test pada SPSS 23. Hasil uji statistik menyatakan bahwa ada perbedaan antara nilai rata-rata kelas eksperimen dan kontrol. kelas. Dengan demikian, disimpulkan bahwa tutor sebaya dalam model pembelajaran berbasis masalah memiliki pengaruh signifikan terhadap keterampilan berpikir kritis. Aspek penting dari keterampilan berpikir dengan nilai tertinggi terletak pada keterampilan menafsirkan.
\end{abstract}

Kata Kunci: Tutor Sebaya, PBL, Keterampilan Berpikir kritis.

\begin{abstract}
The application of problem based learning in the classroom often experiences obstacles, primarily to teach high-level thinking skills, such as critical thinking skills. To overcome these obstacles, in this study we tried the use of peer tutors to guide their friends in a collaborative group when solving problems. This study aims to describe the impact of peer tutoring in problem-based learning on the critical thinking skills of high school physics students. This type of research is a quasi-experimental study with a pretestposttest control group design. The sample of this research is class X MIPA 3 and X MIPA 4 SMAN 4 Jember. One class was given treatment using problem-based learning accompanied by peer tutoring, while one other class only used problem-based learning. Data about critical thinking skills were obtained from the posttest at the end of learning which was then analyzed using the Independent Sample T-test on SPSS 23. The statistical test results stated that there were differences between the average values of the
\end{abstract}


Nasihah, Supeno, Lesmono. - Pengaruh Tutor Sebaya ...

experimental class and the control class. Thus, it is concluded that peer tutoring in the problem-based learning model has a significant effect on critical thinking skills. The essential aspect of thinking skills with the highest value lies in interpreting skills.

Keywords: Peer Tutors, PBL, Critical Thinking.

\section{PENDAHULUAN}

Pendidikan merupakan usaha sadar dan terencana untuk mewujudkan suasana pembelajaran yang membuat peserta didik aktif mengembangkan potensi dirinya untuk memiliki kekuatan spiritual keagamaan, pengendalian diri, kepribadian, kecerdasan, dan akhlak mulia (UU Sisdiknas No 20 Tahun 2003). Pemerintah telah berupaya dalam meningkatkan kualitas mutu pendidikan, salah satunya dengan mengembangkan Kurikulum Tingkat Satuan Pendidikan (KTSP) menjadi Kurikulum 2013 yang bertujuan untuk mempersiapkan warga indonesia menjadi pribadi yang kritis, kreatif, inovatif, dan afektif (Sudewi et al., 2014). Peningkatan kualitas pendidikan harus terus dilakukan, salah satunya dengan cara memberikan ilmu pengetahuan, baik Ilmu Pengetahuan Sosial (IPS) maupun Ilmu Pengetahuan Alam (IPA).
Fisika merupakan salah satu cabang Ilmu Pengetahuan Alam (IPA) yang berkaitan tentang fenomena alam yang sistematik dan dalam penerapan pembelajarannya di sekolah harus mampu menyajikan permasalahan yang terkait dengan kehidupan sehari-hari yang harus diselesaikan oleh peserta didik dengan caramengembangkan kemampuan berpikir tingkat tinggi melalui diskusimaupun percobaan (Saputri et al., 2016). Pembelajaran pada abad ke-21 mewajibkan siswa untuk memiliki beberapa kemampuan berpikir tingkat tinggi, salah satunya yaitu keterampilan berpikir kritis (Anggraeni et al., 2016). Keterampilan berpikir kritis merupakan keterampilan yang difokuskan pada pengambilan keputusan, menganalisis, dan mengevaluasi suatu permasalahan yang dapat dipertanggungjawabkan (Solihin et al., 2018).Keterampilan berpikir kritis penting dimiliki siswa untuk melatih tanggung jawab dan 
Nasihah, Supeno, Lesmono. - Pengaruh Tutor Sebaya ...

melatih keterampilan dalam aktif selama pembelajaran. menganalisis dan menyelesaikan Pembelajaran yang kurang berbagai permasalahan (Redhana, melibatkan siswa secara aktif dapat 2010). Keterampilan berpikir kritis juga digunakan untuk menyiapkan peserta didik dalam menghadapi kehidupan pada masa datang yang penuh tantangan dan persaingan (Nikita et al., 2018).

Pembelajaran saat ini masih didominasi oleh guru, sehingga siswa menjadi pasif dan tidak kreatif (Dwi et al., 2013). Menurut Wisudawati dan Anggaryani (2014), proses pembelajaran yang saat ini sering dilakukan olegguru adalah dengan cara menjelaskan materi dan siswa mendengarkan secara pasif, sehingga siswa cenderung cepat melupakan materi yang telah diberikan. Anggraeni et al. (2016) menyatakan bahwa dengan proses pembelajaran tersebut, siswa hanya bisa mengerjakan soal yang bersifat mengingat dan menjelaskan serta belum bisa mengerjakan soal yang bersifat menganalisis sehingga hal tersebut dapat berdampak pada rendahnya keterampilan berpikir kritis siswa.Hal ini dikarenakan kurangnya melibatkan siswa secara menyebabkan tidakseimbangnya kemampuan kognitif, afektif, dan psikomotorik siswa (Setyorini et al., 2011).

Berdasarkan studi International Program for International Student Assessment (PISA) bahwa kemampuan literasi siswa Indonesia pada tahun 2015 berada pada peringkat ke-61 dari 70 negara dengan skor rata-rata 403 (OECD, 2016). Menurut Nizam (2016), selama 2 periode penelitian terakhir PISA, Indonesia mengalami peningkatan skor sains, yaitu 382 pada tahun 2012 dan 403 pada tahun 2015 namun belum mencapai skor rata-rata dari yang telah ditetapkan PISA sejumlah 500. Hal ini didukung oleh hasil penelitian Djufri dan Wilujeng (2017) yang menyatakan bahwa siswa Indonesia lemah di semua aspek kemampuan, baik matematika maupun sains sehingga perlunya penguatan dalam hal kemampuan mengintegrasikan berbagai informasi, menggeneralisir pengetahuan yang dimiliki, dan 
Nasihah, Supeno, Lesmono. - Pengaruh Tutor Sebaya ...

menarik kesimpulan yang merupakan salah satu dari keterampilan berpikir kritis.

Keterampilan berpikir kritis dapat dilatih dengan memberikan permasalahan kepada siswa selama pembelajaran agar mereka saling bertukar pikiran dan bekerjasama untuk memecahkan permasalahan yang diberikan (Setyorini et al., 2011). Salah satu model pembelajaran yang mampu meningkatkan keterampilan berpikir kritis siswa adalah model Problem Based Learning (PBL). Model PBL merupakan salah satu model pembelajaran yang menuntut siswa untuk mencari solusi dari permasalahan yang diselesaikan secara berkelompok (Setyorini et al., 2011).

Model Problem Based Learning (PBL) merupakan model pembelajaran yang menggunakan permasalahan secara nyata di sekitar lingkungan siswa untuk memperoleh pengetahuan dan konsep melalui kemampuan berpikir kritis dan memecahkan masalah (Fakhriyah, 2014).
Hal ini sejalan dengan pendapat Yuan (2008) yang menyatakan bahwa PBL mampu mengarahkan siswa belajar secara mandiri sehingga dapat meningkatkan keterampilan berpikir kritis dan menganalisis permasalahan yang ada di dunia nyata.

\section{Model Problem Based Learning} pada realitanya membutuhkan waktu yang lama untuk mampu menumbuhkan keterampilan berpikir kritis siswa, karena terdapat beberapa hal yang mempengaruhi hubungan model Problem Based Learning dengan keterampilan berpikir kritis, seperti usia, jenis kelamin, prestasi akademik, dan latar belakang (Yamin dan Masek, 2011). Kirschner et al. (2006) juga mengatakan bahwa penerapan model Problem Based Learning membutuhkan waktu yang lama dalam pelaksanaannya. Kelemahan yang terlihat di kelas, selain memerlukan waktu yang lebih lama juga adanya langkah-langkah pembelajaran yang banyak dalam model ini (Masyhuri et al., 2017).

Choo et al. (2011) menyarankan penggunaan tutor agar pembelajaran dengan menerapkan model Problem Based Learningdapat berlangsung 
Nasihah, Supeno, Lesmono. - Pengaruh Tutor Sebaya ...

secara efektif, salah satunya dengan menggunakan tutor sebaya. Metode tutor sebaya merupakan metode pembelajaran yang memberdayakan salah satu siswa yang memiliki kemampuan lebih dibandingkan teman lainnya dan bertugas menyampaikan materi pada kelompoknya dengan perjanjian tertentu sehingga tercipta kelompok yang kooperatif (Arjanggi dan Suprihatin, 2010). Teori Zone of Proximal Development (ZPD) dari Vygotsky (1978) menyatakan bahwa belajar dapat membangkitkan proses mental seseorang yang tersimpan dengan cara berinteraksi, baik dengan orang dewasa atau berkolaborasi dengan sesama teman. Pengembangan kemampuan dalam melakukan penyelsaian masalah dapat dikembangkan dengan cara mengkondisikan proses interaksi antar siswa atau dengan tutor sebaya. Hal inilah yang melandasi penerapan model problem based learning disertai tutor sebaya dalam pembelajaran fisika.

Qudsi (2014) menyatakanbahwa tutor sebaya dapat diterapkan dengan caramenugaskan salah satu siswa yang memiliki pemahaman lebih tinggi untuk mengajarkan kepada temannya yang kurang paham dalam kelompoknya. Selain itu, inti dari metode tutor sebaya adalah membagi siswa ke dalam kelompok-kelompok kecil dengan menggunakan sumber belajar teman sebayanya yang lebih menguasai materi.

Hasil penelitian yang dilakukan oleh Esther et al. (2011) menyarankan penggunaan tutor sebaya pada pembelajaran fisika berbasis masalah karena tutor sebaya berperan pada proses pembelajaran fisika, terutama dalam proses peningkatan pembelajaran dan pencapaian siswa. Hal ini dikarenakan pencapaian tertinggi siswa terletak pada bimbingan yang efektif dan kemampuan interaksi antar siswa dengan menggunakan bahasa yang mudah dipahami oleh siswa (Schmidt dan Moust, 1995). Hal ini lebih mudah dilakukan jika proses komunikasi dilakukan dengan teman sebaya siswa.

Tutor sebaya pada model problem based learning merupakan alternatif yang dapat digunakan untuk meningkatkan keterampilan berpikir 
kritis pada siswa SMA. Siswa dapat melatih keterampilan berpikir kritisnya dengan menyelesaikan dan menganalisis serta membuktikan permasalahan-permasalahan yang telah diberikan dengan dibantu oleh tutor sebaya yang memiliki pemahaman lebih tinggi (Nasihah et al., 2018). Siswa juga mendapat banyak informasi dari tutor sebayanya, selain itu siswa tidak merasa canggung apabila ada hal yang kurang dimengertinya.

Berdasarkan uraian tersebut, maka perlu dilakukan penelitian terkait pengaruh tutor sebaya pada penerapan model problem based learning terhadap keterampilan berpikir kritis fisika siswa SMA.

\section{METODE}

Jenis dari penelitian ini adalah quasi eksperimen dengan menggunakan desain penelitian pretest posttest control goup design. Penelitian dilakukan menggunakan dua kelas, yaitu kelas eksperimen dan kelas kontrol yang dilaksanakan di kelas X MIPA 3 dan X MIPA 4 SMAN 4 Jember pada tahun ajaran 2018/2019.Kelas eksperimen sebagai kelas yang menerima pelajaran tutor sebaya pada pembelajaran model problem based learning, sedangkan kelas kontrol sebagai kelas yang menerima pelajaran dengan menggunakan model problem based learning saja. Pembelajaran dilakukan pada materi memadu gerak. Pemilihan tutor didasarkan pada kriteria, yaitu siswa yang memiliki akademik lebih bagus daripada lainnya, mampu berkomunikasi secara lancar, dan mampu memberikan penjelasan dengan baik kepada temannya.

Pengumpulan data dilakukan dengan tes tulis berupa soal essay berjumlah 5 soal yang sudah disesuaikan dengan indikator keterampilan berpikir kritis.Indikator keterampilan berpikir yang diukur saat tes meliputi keterampilan interpretasi, evalusi, interferensi, eksplanasi, dan analisis. Tes dilakukan pada awal pembelajaran (pre-test) untuk mengetahui kemampuan awal kedua kelas dan tes di akhir pembelajaran (post-test) untuk melihat pengaruh dari tutor sebaya dalam model problem-based 
Nasihah, Supeno, Lesmono. - Pengaruh Tutor Sebaya ...

learning terhadap keterampilan pada pembelajaran PBL (Problem berpikir kritis.

Based Learning) terhadap

Pengaruh tutor sebaya pada model keterampilan berpikir kritis siswa.

problem based learning terhadap Data keterampilan berpikir kritis keterampilan berpikir kritis diuji siswa diperoleh melalui post-test yang menggunakan uji Independent Sample dilakukan di akhir pembelajaran pada t-test dengan bantuan SPSS 23. Uji materi gerak parabola, baik pada statistik dilakukan terhadap nilai post- kelas eksperimen maupun kelas test kelas kontrol dan kelas kontrol.Data hasil post-test eksperimen.

\section{HASIL DAN PEMBAHASAN}

keterampilan berpikir kritis pada kelas eksperimen dan kelas kontrol ditunjukkan pada Tabel 1.

Tujuan dari penelitian ini adalah untuk mengkaji pengaruh tutor sebaya

Tabel 1. Data hasil post-test keterampilan berpikir kritis

\begin{tabular}{ccc}
\hline $\begin{array}{c}\text { Aspek } \\
\text { Keterampilan } \\
\text { Berpikir Kritis }\end{array}$ & $\begin{array}{c}\text { Rata-rata } \\
\text { Kelas Eksperimen }\end{array}$ & $\begin{array}{c}\text { Rata-rata Kelas } \\
\text { Kontrol }\end{array}$ \\
\hline Interpretation & 98,57 & 94,29 \\
Evaluation & 97,59 & 73,94 \\
Interfence & 96,57 & 38,86 \\
Explanation & 96,19 & 69,05 \\
Analysis & 68,38 & 24,57 \\
Rata-rata & $\mathbf{9 1 , 5 0}$ & $\mathbf{6 0 , 1 0}$ \\
SD & $\mathbf{1 2 , 9 4}$ & $\mathbf{2 8 , 0 8}$ \\
\hline
\end{tabular}

Berdasarkan Tabel 1 dapat aspek menginterpretasi. Nilai diketahui bahwa nilai keterampilan terendah yang dicapai,baik pada kelas berpikir kritis yang diperoleh siswa eksperimen maupun kelas kontrol bervariasi. Nilai tertinggi yang terdapat pada aspek analisis.Rata-rata dicapai,baik pada kelas eksperimen keterampilan berpikir kritis kelas maupun kelas kontrol terdapat pada kontrol dan kelas eksperimen 
berbeda, kelas eksperimen sebesar

91,5 dan kelas kontrol sebesar 60,1.

Hasil uji normalitas digunakan untuk mengetahui bahwa data keterampilan berpikir kritis siswa terdistribusi dengan normal dimana data keterampilan berpikir kritis siswa dikategorikan normal apabila signifikansi kelas eksperimen dan kelas kontrol lebih dari 0,05. Hasil ujinormalitas ditunjukkan pada Tabel 2.

Tabel 2.Uji normalitas data keterampilan berpikir kritis.

\begin{tabular}{|c|c|c|c|}
\hline & & Berpikirkritis & Kelas \\
\hline $\mathrm{N}$ & & 35 & 35 \\
\hline \multirow{2}{*}{ Normal Parameters ${ }^{\mathrm{a}, \mathrm{b}}$} & Mean & 91,50 & 60,09 \\
\hline & Std. Deviation & 5,567 & 11,781 \\
\hline \multirow[t]{3}{*}{ Most Extreme Differences } & Absolute & , 128 & ,136 \\
\hline & Positive & ,075 & ,090 \\
\hline & Negative &,- 128 &,- 136 \\
\hline Test Statistic & &, 128 & , 136 \\
\hline Asymp. Sig. (2-tailed) & &, $157^{\mathrm{c}}$ &, $100^{c}$ \\
\hline
\end{tabular}

Berdasarkan data pada Tabel 2 melakukan uji normalitas, maka didapatkan bahwa nilai dilanjutkan dengan uji independent signifikansinya 0,157 dan 0,100 yang sample t-test. $\mathrm{Uji}$ statistik tersebut berarti lebih dari 0,05 , sehingga data selanjutnya didapatkan hasil keterampilan berpikir kritis sebagaimana ditunjukkan pada Tabel terdistribusi normal. Setelah 3.

Tabel 3.Uji independent sample t-test keterampilan berpikir kritis.

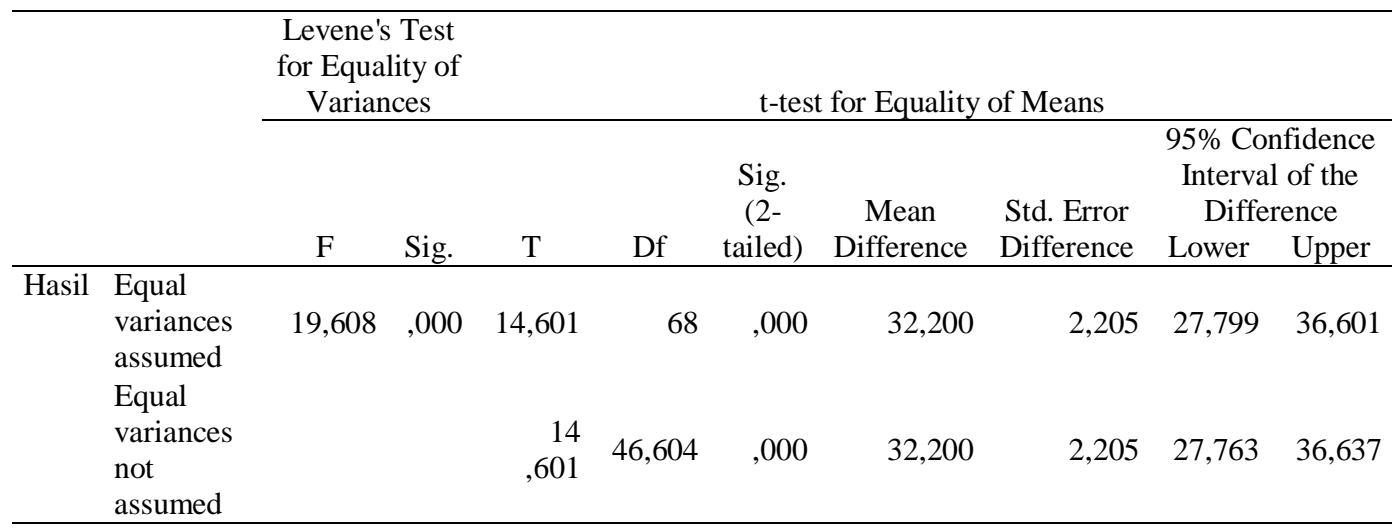


Nasihah, Supeno, Lesmono. - Pengaruh Tutor Sebaya ...

Nilai F pada Levenes's test didapatkan nilai 19,608 dengan signifikansi sebesar 0,00 dengan demikian, nilai signifikansi $\leq 0,05$ sehingga data dikatakan tidak homogen serta pengujian independent sample t-test dilakukan dengan membaca data pada bagian asumsi equal variences not assumsed. Nilai t hitung adalah 14,601 dengan signifikansi (2-tailed) sebesar 0,00. Pengujian hipotesis menggunakan uji dua pihak untuk mencari perbedaan dan dilanjutkan dengan pengujian pihak kanan untuk mencari pengaruh. Hipotesis statistik menyatakan bahwa $\mathrm{H}_{0}$ : keterampilan berpikir kritis siswa pada kelas eksperimen sama dengan siswa kelas kontrol dan $\mathrm{H}_{\mathrm{a}}$ : keterampilan berpikir kritis siswa kelas eksperimen berbeda darikelas kontrol. Nilai signifikansi (2-tailed) sebesar 0 dibagi 2 hasilnya 0 , nilai 0 $<0,05$ sehingga berdasarkan kriteria pengujian statistik dapat dinyatakan bahwa $\mathrm{H}_{0}$ ditolak dan dapat dikatakan bahwa terdapat perbedaan antara nilai rata-rata kelas eksperimen dan kelas control.Berdasarkan hasil pengujian tersebut didapatkan bahwa tutor sebaya pada pembelajaran model problem based learning berpengaruh secara signifikan terhadap keterampilan berpikir kritis siswa.

Pembelajaran pada penelitian ini dilakukan dengan menerapkan tutor sebaya pada model problem based learning.Sebelum pembelajaran dimulai, tutor dipilih berdasarkan beberapa kriteria seperti siswa yang memiliki kemampuan akademik lebih tinggi, siswa yang mampu menjelaskan dan berkomunikasi dengan baik, serta siswa yang mampu mengajarkan materi kepada teman sebayanya.Setelah terpilih beberapa siswa yang layak menjadi tutor, selanjutnya dilakukan pelatihan kepada siswa yang berperan sebagai tutor. Pelatihan ini bertujuan untuk memberikan gambaran proses pembelajaran dan tugas tutor selama pembelajaran.

Tahap pertama pada pembelajaran problem based learningadalah tahap orientasi masalah. Pada tahap ini, siswa terlebih dahulu dibagi kedalam kelompok dan diberikan permasalahan.Tutor sebaya berperan memotivasi teman-temannya agar berpendapat mengenai permasalahan yang ada, memberikan stimulus agar 
Nasihah, Supeno, Lesmono. - Pengaruh Tutor Sebaya ...

teman-temannya berpendapat dan mampu mengaitkan permasalahan dengan kehidupan sehari-hari.

Tahap kedua pembelajaran adalah mengorganisir masalah.Pada tahap ini, tutor membantu teman-temannya untuk menuliskan hipotesis dari permasalahan yang diberikan. Tutor hanya bertugas membantu dalam merumuskan hipotesis masalah tanpa mengoreksi benar atau salah pendapat dari teman-temannya.

Tahap ketiga pembelajaran adalah membimbing penyelidikan individu dan kelompok.Pada tahap ini, tutor membantu teman-temannya melakukan pengumpulan data dan informasi untuk membuktikan benar salahnya hipotesis yang telah dibuat. Tutor membantu siswa yang merasa kebingungan dan memandu aktivitas pengumpulan data dan informasi. Siswa melakukan kegiatan sesuai arahan tutor dan bertanya hal-hal yang tidak dipahaminya selama proses pembelajaran. Pada tahap ini sudah diketahui apakah hipotesis yang diajukan sesuai atau tidak dengan data yang didapat. Siswa juga menganalisis mengapa hal-hal tersebut bisa terjadi.
Tahap keempat pembelajaran adalah mengembangkan dan menyajikan karya.Pada tahap ini, tutor berperan membantu siswa dalam menyajikan karya hasil perolehan data yang disajikan dalam beberapa representasi. Selain itu, setiap kelompok maju ke depan kelas untuk mempresentasikan hasil perolehan data dan diskusi yang telah dilakukan bersama kelompoknya. Tahap kelima pembelajaran adalah melakukan evaluasi.Pada tahap ini, guru membantu siswa untuk melakukan refleksi terhadap permasalahan yang telah dipelajari, guru meluruskan halhal yang berkaitan dengan permasalahan yang telah diberikan.

Tutor sebaya pada pembelajaran problem based learning (PBL) berperan mulai awal pembelajaran, yaitu sejak dibentuknya kelompokkelompok siswa. Perhatian siswa dipusatkan kepada tutor sebaya karena dengan adanya tutor sebaya pada setiap kelompok, penyelesaian masalah menjadi lebih cepat.Selain itu, siswa juga dirangsang untuk mengemukakan pendapat. Pada saat siswa mengajukan pendapat, perlahan-lahan keterampilan berpikir 
kritis siswa mulai terlatih. Siswa berusaha mengaitkan permasalahan yang dijukan dengan fenomena sehari-hari yang pernah dialami atau yang ada di lingkungan sekitarnya. Selanjutnya siswa berusaha untuk melakukan perolehan data untuk membuktikan hipotesis yang dipandu langsung oleh tutor sebaya.Dengan adanya tutor sebaya, siswa tidak takut untuk bertanya mengenai hal yang kurang dipahaminya.

Tugas tutor selanjutnya adalah menuntun siswa untuk menarik kesimpulan dari hasil perolehan data dan meninjau kembali apakah hipotesis awalnya sama dengan hasil perolehan data atau tidak. Dalam proses ini siswa dilatih untuk mengembangkan beberapa aspek dari keterampilan berpikir kritis, yaitu kemampuan

menganalisis,menyimpulkan, dan menjelaskan hal-hal yang berkaitan dengan permasalahan yang diajukan.

Setelah menganalisis data bersama tutor, siswa mempresentasikan hasil karyanya di depan kelas.Presentasi ini bertujuan untuk memperoleh kesepakatan dari apa yang dibahas pada permasalahan tersebut. Setelah melakukan presentasi, guru melakukan evaluasi atau meluruskan hal-hal yang dirasa perlu untuk menambah pengetahuan siswa.

Penelitian ini dilakukan selama tiga pertemuan, dimana pada setiap pertemuan, peran tutor memiliki porsi yang berbeda.Pada pertemuan pertama, peran tutor lebih banyak membantu siswa karena kebanyak siswa masih kebingungan dalam menganalisis masalah dan melaksanakan perolehan data untuk membuktikan dan menjawab permasalahan yang diajukan.Pada pertemuan kedua dan ketiga, siswa sudah mulai paham sehingga peran tutor tidak sebesar pada pertemuan pertama. Tutor sebaya pada penelitian ini bertugas membantu siswa untuk mengembangkan keterampilan berpikir kritis lewat beberapa kegiatan, yaitu membantu siswa untuk menganalisis dan menyelesaikan permasalahan, mengaitkan permasalahan dengan fenomena dalam kehidupan sehari-hari, serta mengevaluasi permasalahan yang diberikan.

Berdasarkan penjelasan diatas dapat dikatakan bahwa keterampilan 
Nasihah, Supeno, Lesmono. - Pengaruh Tutor Sebaya ...

berpikir kritis bukan merupakan keterampilan yang berkembang dengan sendirinya, tetapi harus dilatih dengan memberikan stimulus yang mampu menuntut siswa untuk berpikir kritis.Selain itu, menurut penelitian yang dilakukan Setyorini et al (2011) perlunya pemberian masalah kepada siswa selama pembelajaran agar siswa saling bertukar pikiran dan bekerjasama untuk membantu memecahkan masalah sehingga dapat melatih keterampilan berpikir kritis. Model pembelajaran yang mampu mengembangkan keterampilan berpikir kritis siswa yaitu pemberian model pembelajaran yang menghadapkan siswa pada suatu permasalahan dan mampu membuat siswa berinisiatif untuk menemukan konsep dan belajar mandiri (Afrizon et al., 2012).

\section{KESIMPULAN DAN SARAN}

\section{Kesimpulan}

Berdasarkan hasil penelitian ini dapat disimpulkan bahwa terdapat pengaruh tutor sebaya pada pembelajaran model problem based learning terhadap keterampilan berpikir kritis. Dengan demikian dapat dikatakan bahwa terdapat perbedaan antara nilai rata-rata kelas eksperimen dan kelas kontrol.Berdasarkan hasil uji statistik didapatkan bahwa tutor sebaya pada pembelajaran model problem based learning berpengaruh secara signifikan terhadap keterampilan berpikir kritis siswa.

\section{Saran}

Berdasarkan hasil penelitian maka peneliti menyarankan bahwa penerapan tutor sebaya pada model problem based learning (PBL) dapat digunakan dalam pembelajaran fisika sehingga dapat meningkatkan partisipasi siswa serta mampu menggali berbagai informasi selama pembelajaran. Penelitian ini dapat dikembangkan pada pokok bahasan yang berbeda, sehingga diharapkan keterampilan berpikir kritis siswa dapat dikembangkan.

\section{DAFTAR PUSTAKA}

Afrizon, R., Ratnawulan, \& Fauzi, A. (2012). Peningkatan perilaku berkarakter dan keterampilan berpikir kritis siswa kelas IX MTsN Model Padang pada mata pelajaran ipa-fisika menggunakan model problem based instruction. 
Nasihah, Supeno, Lesmono. - Pengaruh Tutor Sebaya ...

Jurnal Penelitian Pembelajaran Fisika. 1, 1-16.

Anggraeni, Y. N., Prayitno, B. A., \& Ariyanto, J. (2016). Penerapan model konstruktivis-metakognitif pada materi sistem koordinasi untuk meningkatkan kemampuan berpikir kritis siswa kelas XI MIA 1 SMA Negeri 6 Surakarta tahun pelajaran 2015/2016. Jurnal BioPedagogi. 5(2), 48-55.

Arjanggi, R. \& Suprihatin, T. (2010). Metode pembelajaran tutor teman sebaya meningkatkan hasil belajar berdasarkan regulasi-diri. Jurnal Sosial Humaniora, 14(2), 91-97.

Choo, S. S. Y., Rotgans, J. I., Yew, E. H. J., \& Schmidt, H. G. (2011). Effect of worksheet scaffolds on student learning in problem-based learning. Advanced in Health Science Education. 16, 517-528.

Djufri, E. \& Wilujeng, I. (2017). The influence of ssb based on lab work toward science process skills of students. Jurnal Pendidikan Matematika dan Sains,4(2), 125133.

Dwi I. M., Arif, H. \& Sentot, K. (2013). Pengaruh strategi Problem Based Learning berbasis ICT terhadap pemahaman konsep dan kemampuan pemecahan masalah fisika. Jurnal Pendidikan Fisika Indonesia,9(1), 8-17.

Esther, C., Yew, E. H. J., \& Schmidt, H.G. (2011). Effects of tutorbehaviours on the process of problem based learning. Advance in Health Science Education,16(4), 491-503.

Fakhriyah, E. (2014). Penerapan problem based learning dalam upaya mengembangkan

kemampuan berpikir kritis mahasiswa. Jurnal Pendidikan IPA Indonesia,3(1), 95-101.

Kirschner, P.A., Sweller, J. \& Clark, R. E.(2006). Why minimal guidance during instruction does not work : an analysis of the failure of constructivist, discovery, problem-based, experiential, and inquiry based teaching. Educational Psychologist,41(2), 75-86.

Masyhuri, Lesmono, A. D., \& Handayani, R. D. (2017). Model Problem Based Learning (PBL) disertai tugas dalam pembelajaran fisika di SMA.Jurnal Pembelajaran Fisika,6(4), 418426.

Nasihah, E.D., Supeno, \& Lesmono, A.D. (2018). Model Problem Based Learning (PBL) disertai tutor sebaya untuk meningkatkan keterampilan berpikir kritis siswa SMA.Prosiding Seminar Nasional Pendidikan Fisika. 3(2), 25 November 2018. FKIP e-prociding : 178-183.

Nikita, P. M., Lesmono, A.D., \& Harijanto, A. (2018). Pengembangan e-modul materi dinamis untuk meningkatkan kemampuan berpikir kritis siswa SMA kelas XI. Jurnal Pembelajaran Fisika,7(2), 175180.

Nizam. (2016). Ringkasan Hasil-hasil Asesmen: Belajar UN, PISA, TIMSS, INAP, Puspendik. Jakarta: Balitbang Kemdikbud.

OECD. (2016). PISA 2015 Result: Snapshot of Performance in 
science, reading in mathematics. Canada: OECD.

Qudsi, I. (2014). Pembelajaran tutor sebaya materi besaran dan satuan fisika. Jurnal Dinamika,4(3), 1-10.

Redhana, I. W. (2010). Pengaruh model pembelajaran berbasis peta argumen terhadap keterampilan berpikir kritis siswa pada topik laju reaksi.Jurnal Pendidikan dan Pengajaran,43(2), 141-148.

Saputri, K., Muslim, M., \& Murniati. (2016). Pengaruh model problem based learning terhadap keterampilan menyimpulkan hasil percobaan siswa pada pembelajaran fisika di kelas $\mathrm{X}$ SMA Negeri 1 Tanjung Lubuk. Jurnal Inovasi dan Pembelajaran Fisika,3(1), 1-8.

Schmidt, H.G, \& Moust J. H. C. (1995). What makes a tutor effective? A structural equations modeling approach to learning in problem based curricula. Academic medicine, 70, 708-714.

Setyorini, U., Sukiwo, S.E., \& Subali, B. (2011). Penerapan model Problem Based Learning untuk meningkatkan kemampuan berpikir kritis siswa SMP. Jurnal Pendidikan Fisika Indonesia,7(2), 52-66.

Solihin, M.W., Prastowo, S.H.B., \& Supeno. (2018). Pengaruh model pembelajaran inkuiri terbimbing terhadap kemampuan berpikir kritis siswa SMA. Jurnal Pembelajaran Fisika,7(3), 299 306.

Sudewi, N. L., Subagia, I. W., Tika, I. N., \& Si, M. (2014). Studi komparasi penggunaan model pembelajaran problem based learning (pbl) dan kooperatif tipe group investigation (gi) terhadap hasil belajar berdasarkan taksonomi Bloom. Jurnal Pendidikan dan Pembelajaran IPA Indonesia, 4(1).

Undang-undang Republik Indonesia Nomor 20 Tahun 2003. Sistem Pendidikan Nasional. 2003. Jakarta: Diundangkan oleh Sekretaris Negara Republik Indonesia.

Vygotsky, L.S. (1978). Mind in Society. Cambridge, MA: Harvard University Press.

Wisudawati, A. \& Anggaryani, M. (2014). Penerapan pembelajaran fisika berdasarkan strategi Brain Based Learning untuk meningkatkan keterampilan berpikir kritis siswa pada materi elastisitas kelas XI di SMA Negeri 1 Wonodayu Sidoarjo.Jurnal Inovasi Pendidikan Fisika,3(2), 15.

Yamin, S., \& Masek, A. (2011). The effect of Problem Based Learning on critical thinking ability: A theoretical and empirical review. International Review of Social Sciences and Humanities, 2(1), 215-221.

Yuan. (2008). Promoting critical thinking skill through problem based learning. Journal of Social Science and Humanistic.2(2), 85100. 